\title{
Racial Microaggression in Multicultural Malaysia: Ethnic-specific Experience of University Students
}

\author{
Mitshel Lino ${ }^{1}$ and Intan H.M. Hashim \\ School of Social Sciences, Universiti Sains Malaysia, Penang, Malaysia
}

\begin{abstract}
Contemporary studies on racial microaggression in Southeast Asian countries, particularly those that take into account the experience of people from different ethnic groups, are limited. As such, the current study focused on racial microaggression experience amongst Malaysian university students from different ethnic groups. A sample of 40 university students was recruited through purposive and snowball sampling strategies. The participants comprised of nine ethnic Malays, 10 ethnic Chinese, 10 ethnic Indians, seven ethnic groups from East Malaysia and four of mixed-parentage. A qualitative method using semi-structured individual interviews was utilized. Responses/verbatim from the interviews were analyzed using Interpretative Phenomenological Analysis (IPA) method. Results indicated 11 common racial microaggression themes reported by participants across most ethnic groups, including 'In-group benefit' and 'The paradox of over-scrutiny/ overlook.' Also, five ethnic-specific themes, such as 'Pathologizing cultural values/ communication style' and 'Ignorant about the situation in Sabah \& Sarawak.' The findings indicate that while there can be a shared experience of racial microaggression for people of different ethnicities, the actual themes experienced by specific ethnic groups may differ. Theoretical and practical implications include recommendations on how to address the issue in Malaysia.

Keywords: racial microaggression, subtle racism, multi-ethnicities microaggression, Malaysia; Southeast Asia.
\end{abstract}

\section{Introduction}

Malaysia as a country and Malaysian public universities as an institution has an increasingly diverse population in which people of different backgrounds need to closely interact with one another (Mustapha, Azman, Karim, Ahmad \& Lubis, 2009; Tamam \& Krauss, 2017). Thus, there is a greater need to promote national unity and opportunity for interaction among different races and ethnic groups through education or educational institutions. The national government has implemented various efforts, such as the introduction of Islamic and Asian Civilizations "TITAS" (Tamadun Islam dan Tamadun Asia) and Ethnic Relation (Hubungan Etnik) as compulsory national university modules to promote intercultural awareness (Husain \& Kadir, 2012; Nasir, Ghani, Salamat \& Husain, 2018). The effectiveness of such modules was questioned when Ab Rahman and colleagues (2011) found that the interethnic social relationship among the freshmen of a public university was relatively moderate despite the introduction of these modules.

Indeed, research suggested that Malaysian higher education institutions failing to unite the diverse groups (Segawa, 2007). Some of the issues in Malaysian universities are related to policies and practices including the implementation of positive discrimination in university enrolment, scholarship and financial assistance favoring the Bumiputera or "sons of soil", such as: affirmative action (Lee, 2012), preferential policies (Raman \& Tan, 2010), ethnic quota policy, effect on quality, SES effect, and ethnic group effect (Tzannatos, 1991). These policies and practices may result in worsening inter-ethnic relations among students of different ethnicities. Negative inter-ethnic relations often reflected in the number of conflicts and aggressions characterizing the interactions (Calderon, 2019; Silalahi \& Yuwono, 2018). This study sets to examine one form of aggression, i.e., racial microaggression. We argue that while the studies on inter-ethnic relations in Malaysian universities have focused on unfair practices in Malaysian

\footnotetext{
${ }^{1}$ Correspondent e-mail: mitshel.mitshel@gmail.com
} 
universities, few have examined racial microaggression. The present study intends to address this research gap by focusing on racial microaggression incidence in Malaysian universities.

\section{Multicultural Malaysia}

Malaysia, with a population estimate of 32.4 million in 2018 (Department of Statistics Malaysia, 2018), is a pluralistic society that comprises a heterogeneous population, marked by non-rigid ethnic boundaries and meaning of ethnicity (Hirschman, 1987). The ethnic composition comprises of Bumiputera or "sons of the soil" (69.1\%), ethnic Chinese (23.0\%), ethnic Indian (6.9\%), and ethnic 'others' (1.0\%) (Department of Statistics Malaysia, 2018). The ethnic Chinese and Indian groups were initially immigrants from China and India, respectively; they are citizens who have resided in Malaysia for three to four generations. The classification of Bumiputera is further broken down into ethnic Malay and indigenous people of Sabah and Sarawak. The ethnic 'others' comprises of Eurasians, Thais, Europeans, and others not classified under the three major ethnic groups (Hirschman, 1987). Within this already diverse ethnic distribution, each group generally practices different religions and uses different mother tongues (Hashim, Mohd-Zaharim, \& Khodarahimi, 2012). For instance, Malays who represent the majority of the Malaysian populations are mostly Muslims and use mainly the Malay language and have distinctive customs and cultures in comparison to the ethnic Indians, who mostly practice Hindu as religion and generally speak Tamil as their mother tongue (Kessler, 1992). The differences among ethnic groups in Malaysia represent more than just race and ethnicity. Ethnic groups in Malaysia are also different not only in terms of their physical attributes; they are also different in terms of religions, cultural values, and beliefs, and also the languages used.

Such a situation illustrates the overlapping ethnic boundaries and the meaning of ethnicity in Malaysia, which is marked by combinations of religions and languages even within a single ethnic category (Hirschman, 1987). Moreover, many interethnic marriages have blurred the distinction between traditional ethnic classification and resulted in unique ethnic combinations (Hirschman, 1987; Nagaraj, 2009; Yigit \& Tatch, 2017). In such a diverse society, cross interaction among people may increase awareness of one's group; thus, promoting a social categorization process that may promote intergroup prejudice and conflicts. In modern days, such perpetuation of prejudice and conflicts may often be translated into a subtler form of racism, such as racial microaggression. What is unique about these interactions is that the groups differ not only on one aspect, i.e., ethnicity but also on other aspects including religion, faith and belief, and mother tongues. It is crucial to examine how the interactions between them can potentially lead to racial microaggression. Such an issue may spark interest to researchers from other countries where inter-religious/inter-linguistic relations further complicate the inter-ethnic relations.

\section{Racial Microaggression}

The term racial microaggression was introduced by Sue, Bucceri, Lin, Nadal, and Torino (2007a); they defined it as "brief and commonplace daily verbal, and behavioral and environmental indignities, whether intentional or unintentional, that communicate hostile, derogatory or negative racial slights and insults that potentially have harmful or unpleasant psychological impact on the target person or group" (p.72). In other words, it is a common and indirect form of racism performed in both verbal and non-verbal forms, automatically, and often unconsciously.

The impact of racial microaggression lies in its invisibility and innocuous nature to the perpetrators and frequently, to the recipients (Pierce, Carew, Pierce-Gonzalez, \& Wills, 1977; Sue et al., 2007b). Consequently, it often prevents people from realizing that their actions and attitudes may be discriminatory (Sue, 2004). More evolving societal values and norms that emphasize egalitarian values and civil laws of many countries prohibit public expression of racial prejudice and discrimination (James, 2019; Sue et al., 2007a). For instance, many Caucasian Americans may believe that they are decent human beings with faith in equality and democracy (Sue et al., 2007b). They may find it hard to believe that they harbor racial prejudice or perform racial discrimination (Sue, 2004), especially when racial microaggression acts can be excused for seemingly nonbiased and valid reasons. The recipient of racial microaggression may often experience a dilemma when alternative explanations seem plausible. They may experience a vague feeling that they may have been attacked, disrespected, or something is amiss (Sue et al., 2007b).

Despite the complex, implicit, and indirect nature of racial microaggression, there are vast documented effects of racial microaggression experience. People who experience racial microaggression have been reported to demonstrate low self-concept (Asamen \& Berry, 1987), negative emotions (Schmitt \& Branscombe, 2002), stereotype threat (Tuitt \& Carter, 2008), internalized emotions (Wang, Leu \& Shoda, 2011), and low self-esteem (WongPadoongpatt, Zane, Okazaki \& Saw, 2017). Consequently, it is essential to understand further the prevalence, impacts, and factors associated with racial microaggression. 
Although the research area on racial microaggressions is rapidly growing in the United States, only a few studies have looked into inter-racial (ethnic) account/ comparison of racial microaggression experiences (Houshmand, Spanierman, \& Tafarodi, 2014). To date, studies on racial microaggressions have mainly concentrated on the experience of a single ethnic group; for instance, African American (Constantine, 2007; Constantine \& Sue, 2007; Sue, Capodilupo, \& Holder, 2008; Allen, 2010), Asian American (Lin, 2010; Sue et al., 2007a; 2007b), and Latina/o American (Rivera, Forquer, \& Rangel, 2010). This phenomenon was illustrated in a meta-analysis review of racial microaggression studies spanning from 2007-2012 by Wong, Derthick, David, Saw, \& Okazaki (2014). It suggested that more studies on racial microaggression and its implications on varying groups are needed. This includes the mediating factors of racial microaggression between and within minority ethnic groups (Wong et al., 2014).

Besides, limited studies were reported on racial microaggression from the Asian context in past literature. Thus far, a few of such studies had been conducted in Malaysia (Lino, 2010; Lino, Hashim, \& Ricardo, 2017), Taiwan (Fan \& Ni, 2013), Japan (Yamada \& Yusa, 2014), and Indonesia (Akun \& Andreani, 2016). One possible explanation for the limited studies on racial microaggression in Malaysia or Asia is the novelty of the concept. Studies related to ethnic relations in Malaysia tend to focus on the more widely known forms of oppression, such as prejudice (Noor, 2007), racism, and discrimination (Neo, 2012). Indeed, as demonstrated by the meta-analysis review of racial microaggressions studies in psychology by Wong et al. (2014), a study from neither Malaysia nor Asia was included in this review.

In a study that investigated university students' experience of racial microaggression in Kuala Lumpur, Malaysia, Lino (2010) conducted three focus group discussions with three groups of ethnic Malay, Chinese, and Indian participants, respectively. Seven themes of racial microaggression emerged, such as 'blame other ethnicities for racist occurrence,' 'lack of awareness of racial microaggression,' and 'perceived and maintained ethnic exclusiveness.' Participants across all ethnic groups generally experienced most of the themes, but some were pertinent to specific ethnicities. For instance, the themes 'second-class citizen' and 'derogatory name-calling' were found to be mostly experienced by the ethnic Chinese and Indian participants. Meanwhile, the ethnic Malay participants experienced a more non-verbal microaggression, such as 'ascription of intelligence' (Lino, 2010). The findings indicated a perpetuation of racial microaggression among the Malaysian undergraduates in a supposedly egalitarian academic institution. It also provided evidence on how different racial microaggression themes can be perpetrated and experienced by people of diverse ethnicities in Malaysia. Also, specific themes were only applicable to members of a particular ethnicity but not to others. More research is needed to understand this phenomenon further.

\section{Racial Microaggression and Ethnic Identity}

Racial microaggression experiences were found to be related to the ethnic identity of either perpetrators or victims (Alabi, 2015). Alabi (2015) studied racial microaggression experience between American minority and nonminority academic librarians. She recruited 139 participants, whereby the majority (70.5\%) identified themselves as Caucasians, and the minority (29.5\%) identified themselves as African American, Hispanic, Asian, Native American, and others. Findings indicated that the librarians from the minority ethnic groups were more likely to report being treated differently by their non-minority peers. Some examples of the themes are 'a colleague has told me that he/she was color-blind,' 'colleague treated me differently than White colleagues,' and 'a colleague has told me that people should not think about race anymore' (Alabi, 2015, p.8). This study suggested that various ethnic groups experienced racial microaggression differently.

There are instances whereby the experience of racial microaggression is not limited to one's ethnic identity. The interplay of "compounding" factors may contribute to racial microaggression. Jones and Galliher (2014) studied the relationship between racial microaggression and the ethnic identity of Native Americans. 114 Native American young adults were recruited from almost 70 distinct native groups. The findings indicated that the majority of the participants experienced at least one type of racial microaggression. The female participants found that microinvalidations to be more upsetting than microinsults (Jones \& Galliher, 2014). Meanwhile, the male participants reported being upset with the experience regardless of the types of racial microaggression (Jones \& Galliher, 2014). Ethnic identity and gender were found to be significantly associated with microaggression experience for a large proportion of Native Americans (Jones \& Galliher, 2014). Male participants were more likely to report such experience when compared to females. This study outlined the distinctive racial microaggression experienced by Native Americans of different genders.

In addition to gender, sexual orientation and religions may also contribute as "compounding factors" towards racial microaggression experience. Elias, Jaisle, and Morton-Padovano (2017) identified the ethnic identity and sexual orientation as factors contributing to racial microaggression occurrences. A quantitative study was conducted using survey questionnaires among 1,093 participants with approximately the same proportion of African Americans, 
Caucasian Americans, and Hispanic Americans. The findings indicated that racial differences in attitudes toward same-sex relations in the United States persisted. African Americans and Hispanic Americans were found to possess unfavorable attitudes toward Lesbian, Gay, and Bisexual (LGB) persons than Caucasian Americans (Elias et al., 2017). However, despite having the least favorable attitudes toward the LGB community of the three racial groups, African American participants were the least likely to engage in microaggressions toward the LGB group (Elias et al., 2017).

The above examples illustrate the influence of "compounding factors" on the experience of racial microaggression. Ethnic identity is a fluid construct, as exemplified by Arslan (2019), who discussed the contested identity of Zazaki speakers due to other equally essential identities. A cross-section of language, religion, culture, region identity, and others contributes to the complexity of one's ethnic identity. Such complexity is reflected in the racial microaggression experience of a particular ethnic group, whereby one's experience may be attributed to various "compounding factors." Individuals with multiple minority status (such as being females, non-majority race or ethnicity, non-heterosexual, and others.) may be plagued with more challenges and more susceptible to racial microaggression experiences.

\section{The Present Study}

This study examined the varying experience of racial microaggression across different ethnic groups. While many studies have explored the experience of racial/ ethnic groups from the western perspective (Wong et al., 2014), more studies are needed to examine the experience of racial/ ethnic groups specific to the Southeast Asian perspective. Hence, this study provides racial microaggression accounts from different ethnic groups in the context of multicultural Malaysia. The study findings may contribute to a greater understanding of racial microaggression, especially in other similar settings of multicultural Asian societies. This objective is summarized in the following research question: What are the ethnic-specific racial microaggression experienced by Malaysian university students within academic settings? When comparing the experience of different groups, we examined them from three different aspects (i) frequency, (ii) themes, and (iii) variation of themes specific to each ethnic group.

\section{Methodology}

The present study employed qualitative design, mainly one-to-one interviews. The data were analyzed through participants' worldview, using the Interpretative Phenomenological Analysis (IPA). IPA is suitable for the present research as it is a highly interpretative and widely used method to explore participants' experience and worldview (attitudes, beliefs, and general reflections) (Langdridge, 2004). It allows the exploration and interpretation of participants' experiences. Through this method, rich information on racial microaggression experience in the Malaysian context was obtained.

The present study has obtained approval from the university's Human Research Ethics Committee and has complied with APA ethical guidelines on human research.

In the present study, the participants were composed of 40 university undergraduates from a government university in North Malaysia. They were 12 males and 28 females between 19 and 25 years of age. Only those studying in the university for at least two years were recruited to ensure proper social adjustment and familiarity with the university environment. The participants were Malaysians who represented all major ethnic groups in the country; there were nine ethnic Malays, 10 ethnic Chinese, 10 ethnic Indians, and 11 ethnic groups classified as 'others' in the present study. The latter included seven from Sabah and Sarawak (East Malaysia) and four mixed parentage participants. There was no participant attrition throughout the study.

Sampling: The researchers recruited the participants through purposive and snowball sampling techniques. Most of the participants were recruited from a general university course. The researchers visited a lecture hall and invited the students to the study. Since participation in the study is voluntary, the researchers distributed basic demographic information forms to students who were interested in taking part in the study. Based on the returned forms, the researchers systematically selected the potential participants based on thorough and equal representations of ethnicity, mother tongue, departments in university, majors, and duration of the study. Subsequently, the researchers contacted the potential participants and arranged for an interview session with those who voluntarily agreed to participate. A small number of participants from the minority groups, i.e., the ethnic Indian and 'Others' were recruited through snowball sampling, due to their small representation in the university. The participants were recruited through recommendations by other participants and from minority student clubs in the university.

Procedure: All interviews were conducted in a one-to-one setting in a vacant classroom, with the presence of a researcher (interviewer) and a participant (interviewee) to ensure participants' comfort and privacy. 
Before every interview session, a researcher briefed the participants on the information of the study, provided informed consent forms, and obtained signatures from participants who voluntarily consented to participate and be audio recorded for the interview. Both English and Malay versions of the information of the study and informed consent forms were available to the participants. Malay is the primary medium of instruction in the university. However, each interview session was conducted in either English, Malay, Hokkien, or Mandarin as an attempt to cater to different spoken language preferences of the interview participants. The interview lasted for about 40 minutes to an hour. The study employed a semi-structured interview with the following two-part interview schedule:

(i) A demographic information form, including the duration of university enrolment, participant's mother tongue, parents' ethnicity, and the participants' ethnicity.

(ii) A set of interview questions were used to assess participants' accounts on broad racial microaggression experience, followed by the experiences on the specific subcategory of racial microaggression (refer to Appendix). The questions were developed by the researchers.

Besides audio recording, field notes were taken during the interview. Toward the end of the interview, the researcher debriefed the participants regarding the possible repercussion from discussing the potentially sensitive interview topic. A debriefing statement form of either Malay or English version was provided. A list of available counseling centers was also provided in case of participants' distress from discussing a sensitive racism-related topic. The researchers exercised the utmost care to ensure no adverse effect on participants' rights and welfare other than minimal fatigue from taking part in the interview.

The participants recruited from the class were given a bonus mark that contributed toward their final course grade, while the participants recruited through snowball sampling outside the class were given a small monetary compensation as a token of appreciation.

Data Analysis: The saturation of data had been achieved when recurring information and repetitive themes emerged from the analysis of the overall participant transcripts. The first researcher transcribed the interview transcripts in verbatim. Non-English interview transcripts were translated accordingly to English for ease of analysis and coding. The transcripts were separately analyzed and coded by both researchers, which were later compared. The presented data indicate stand-alone themes that had been carefully filtered and curated from the sizeable raw interview data.

The interview transcripts were analyzed using the IPA. The data were coded manually without any software. Due to the requirement of IPA, both researchers derived the data by manually reading each interview transcript and interpreting the racial microaggression experience from the context of participants' transcripts. The themes were derived through reading for meaning, identifying themes, structuring themes, producing a summary, and integrating cases (Langdridge, 2004).

Triangulation of data was not performed due to limited resources and time. However, some measurements had been implemented to ensure the reliability and validity of the data. The following techniques correspond to reliability and validity methods frequently utilized by positivists or quantitative researchers (Lincoln \& Guba, 1985): a) credibility (internal validity); b) transferability (external validity/generalizability); c) dependability (reliability); and d) confirmability (objectivity). The researchers had exercised steps to ensure credibility (researchers' prolonged engagement in the research setting to ensure familiarity with the context in which participants experienced racial microaggression, dependability (detailed methodology description), confirmability (two researchers independently coded and later compared the transcripts of the interviews and the first researcher divulged her background as an international student through reflexivity).

Results: The results are classified into the frequency of overall themes and descriptions of themes reported across different ethnic groups and specific ethnic groups. Table 1 indicates the overall themes and frequency of occurrence reported by the participants.

Table 1.

The overall themes and frequency of racial microaggression experiences from each ethnic groups

\begin{tabular}{|c|c|c|c|c|c|}
\hline No. & Overall Themes \& Frequency & Malay & Chinese & Indian & Others \\
\hline 1. & In-group benefit (17) & 5 & 6 & 5 & 1 \\
\hline 2. & The paradox of over-scrutiny/ overlook (12) & 3 & 5 & 2 & 2 \\
\hline 3. & Second-class citizen (11) & 2 & 3 & 5 & 1 \\
\hline 4. & $\begin{array}{l}\text { Assumption of superiority/ inferiority/ intelligence due to } \\
\text { ethnicity (11) }\end{array}$ & 4 & 3 & 2 & 2 \\
\hline 5. & In-group exclusivity (10) & 4 & 2 & 2 & 2 \\
\hline 6. & Insensitivity towards the existence of other ethnicities (7) & 3 & 2 & 1 & 1 \\
\hline
\end{tabular}




\begin{tabular}{llllll}
\hline 7. & Language barrier as a precursor to racial microaggression (6) & 1 & 2 & 2 & 1 \\
8. & $\begin{array}{l}\text { Differential treatment towards people from different ethnicities/ } \\
\text { religion (5) }\end{array}$ & 2 & 1 & 1 & 1 \\
9. & Alien in own land (7) & $\mathbf{x}$ & 2 & 2 & 3 \\
10. & Denial of racial experience (4) & 2 & 1 & 1 & $\mathbf{x}$ \\
11. & Preferential interaction with other ethnicities (2) & 1 & 1 & $\mathbf{x}$ & $\mathbf{x}$ \\
12. & Pathologizing cultural values/communication style (4) & $\mathbf{x}$ & $\mathbf{x}$ & $\mathbf{x}$ & 4 \\
13. $\quad$ Ignorant about the situation in Sabah \& Sarawak (4) & $\mathbf{x}$ & $\mathbf{x}$ & $\mathbf{x}$ & 4 \\
14. & Explicit racial topic/ racial controversy (2) & 2 & $\mathbf{x}$ & $\mathbf{x}$ & $\mathbf{x}$ \\
15. & Perception on sexual availability (2) & $\mathbf{x}$ & 2 & $\mathbf{x}$ & $\mathbf{x}$ \\
16. & Assumption of close-mindedness (1) & $\mathbf{x}$ & $\mathbf{x}$ & 1 & $\mathbf{x}$ \\
\hline Total & & 29 & 30 & 24 & 22 \\
\hline
\end{tabular}

Overall, 16 racial microaggression themes emerged in the present study. The breakdown of the racial microaggression theme rate is indicated based on the frequency reported by each ethnic group. Participants of ethnic Malay and Chinese reported the highest overall frequency of racial microaggression experience, i.e., 29 and 30, respectively. The ethnic Indian and ethnic Sabahan and Sarawakian participants reported a lower incidence of racial microaggression, i.e., 24 and 22, respectively, albeit the frequency difference as compared to that of ethnic Malay and Chinese participants were not significant.

Table 2 indicates 11 general findings of racial microaggression themes. The abbreviations used are ' $\mathrm{P}$ '= Participants and ' $R$ ' $=$ Researchers. The numbers next to the letter ' $\mathrm{P}$ ' are codes assigned to identify the participants. The frequency of the themes and specific ethnicities is also listed in Table 2 in descending order.

Table 2.

Racial microaggression themes experienced by participants across all ethnic groups

\begin{tabular}{|c|c|c|}
\hline No. & Themes, Frequency, \& Ethnicities & Definition \\
\hline 1. & $\begin{array}{l}\text { In-group benefit }(17) \\
\text { All }\end{array}$ & $\begin{array}{l}\text { Members of the same ethnicity received special privilege as } \\
\text { compared to the others }\end{array}$ \\
\hline 2. & $\begin{array}{l}\text { The paradox of over-scrutiny/ overlook } \\
\text { (12) } \\
\text { All }\end{array}$ & One is under the spotlight or ignored due to his/her ethnic identity. \\
\hline 3. & $\begin{array}{l}\text { Second-class citizen }(11) \\
\text { All }\end{array}$ & $\begin{array}{l}\text { Members of an ethnic group were treated unfairly as compared to } \\
\text { the other groups due to their status }\end{array}$ \\
\hline 4. & $\begin{array}{l}\text { Assumption of superiority/ inferiority/ } \\
\text { intelligence due to ethnicity (11) } \\
\text { All }\end{array}$ & $\begin{array}{l}\text { An act/ experience of being looked upon or looked down due to } \\
\text { one's ethnicity }\end{array}$ \\
\hline 5. & $\begin{array}{l}\text { In-group exclusivity }(10) \\
\text { All }\end{array}$ & An act/ experience of isolating one's ethnic group from the others \\
\hline 6. & $\begin{array}{l}\text { Insensitivity towards the existence of } \\
\text { other ethnicities (7) } \\
\text { All }\end{array}$ & $\begin{array}{l}\text { A lack of consideration/ respect towards members from other } \\
\text { ethnic groups }\end{array}$ \\
\hline 7. & $\begin{array}{l}\text { Language barrier as a precursor to } \\
\text { racial microaggression (6) } \\
\text { All }\end{array}$ & $\begin{array}{l}\text { Members of ethnic groups being alienated when others choose to } \\
\text { speak in their mother tongue }\end{array}$ \\
\hline 8. & $\begin{array}{l}\text { Differential treatment towards people } \\
\text { from different ethnicities/ religion (5) } \\
\text { All }\end{array}$ & An act of treating others differently due to their ethnic identities. \\
\hline 9. & $\begin{array}{l}\text { Alien in own land ( } 7) \\
\text { All but ethnic Malays }\end{array}$ & $\begin{array}{l}\text { The members of minority ethnic groups being associated with } \\
\text { non-Malaysian citizens. }\end{array}$ \\
\hline 10. & $\begin{array}{l}\text { Denial of racial experience (4) } \\
\text { All but Others }\end{array}$ & $\begin{array}{l}\text { One's racial experience being brushed off despite an indication of } \\
\text { racial microaggression }\end{array}$ \\
\hline 11. & $\begin{array}{l}\text { Preferential interaction with other } \\
\text { ethnicities ( } 2 \text { ) } \\
\text { Ethnic Malay \& Chinese }\end{array}$ & $\begin{array}{l}\text { One's preference to interact with members of other ethnic group } \\
\text { and undermine members of his or her ethnic group }\end{array}$ \\
\hline
\end{tabular}


Note The data are part of a more extensive data set, portions that were published previously in Lino, Hashim \& Ricardo (2017).

The following are descriptions of 11 racial microaggression themes with samples of the interview excerpt. The selected interview quotes illustrate racial macroaggression themes reported by the participants across all or at least two ethnicities. To illustrate the experience of participants from different ethnic groups in the study, the researchers selected quotes from each ethnicity.

Theme 1: In-group benefit

The participants observed that members of a particular ethnicity shared benefits or information among themselves. If the participants were the member of different ethnicity, they perceived that they were discriminated subtly for not receiving the same equal benefit as of any other students. Such a situation usually happened to people from equal status or standing.

P 29.3 (ethnic Indian): Sometimes we feel that they (coursemates) are so racist and (I feel) disappointed. Because it's like...it's knowledge, you know, you can share it. I don't know why they choose to do that.

Theme 2: The paradox of over-scrutiny/ overlook

Due to the identity of the recipients of racial microaggression, they either became the center of attention or were ignored by others. In the first case, they received negative attention due to their 'unique' traits, while the latter caused them to be avoided or ostracized. Such a different treatment adversely affected the recipients' everyday life because they felt that they could not normally live like other students.

P 15.4 (ethnic Chinese): At first, I thought he (lecturer) didn't hear me. However, I realized that he saw me. I put up my hand, and he didn't want to respond to me. I felt that he was racist as well. This kind of attitude shouldn't be seen here. I mean he is a lecturer; he should treat everybody similarly.

Theme 3: Second-class citizen

The participants perceived that they received unequal statutory rights because of their ethnic identity, especially in terms of public university scholarship, seats in student representation parliament, and others. This happened in an underhanded manner because they do not find any publicized formal statements that specified acceptance quota for a particular ethnicity.

P 23.5 (ethnic Indian): Yeah, when I was in my hometown, I can see my (Indian) cousin, she achieved straight As. But her friends who were Malays got about 5As and managed to acquire JPA scholarship. My other friends, they scored 7As and 9As, but they failed to get the JPA scholarship. Other races like Malay, I won't say Chinese, only Malays with 4As and 5 As can get into matriculation.

Theme 4: Assumption of superiority/ inferiority/ intelligence due to ethnicity

The participants judged others or were seen as superior, inferior, and more/less intelligent based on the stereotype attached to their ethnic identity. Many of them often received unwanted attention or felt the burden of proof if they were perceived to be more superior than what they are. Otherwise, they were looked down on or ostracized if they were seen as inferior.

P 9.1 (ethnic Malay): After the last semester result was announced, everybody was asking about pointer $(G P A)$ ? Then, we tend to gossip about each other, like the Chinese friend, she must have obtained a higher pointer than us.

$R$ : Ok. However, did you or your friend went and asked that Chinese friend about her GPA?

P: No. Because the last semester she was on the Dean's list. Then, we guessed that she may, again, be on the Dean's list.

P 23.1 (ethnic 'Others'): But they still membanding-bandingkan (compare) between them and me. Yeah. Why can people like us (Sabahan) go to university? Why? There are so many questions. That's why I don't want to mix with them because they keep asking the...maybe they are curious, they want to know how we live. It's ok. However, what I'm trying to say is how they are asking me. It's making me like yeah, I feel offended with the way they ask me.

Theme 5: In-group exclusivity

The participants noted the preference of members of an ethnic group to stick together with their group. Such a preference can be explained by their discernment of in-group similarity and out-group difference. 
P 9.3 (ethnic Malay): If they did it within their group behind our back, can it be considered? Sometimes when people from different races, they organized a program or formed a group, they didn't include people from other races. They only included people from the same race.

Theme 6: Insensitivity toward the existence of other ethnicities

The participants experienced/performed discreet acts, whether consciously or unconsciously, that offended or neglected the needs, existence, or feelings of members of different ethnicities and sometimes, religions.

P 22.3 (ethnic Chinese): ...they know that Chinese (professing a certain religious belief) don't eat beef, right? They only prepare food that suits the Malays. We Chinese also eat the same food. The event is actually (from) morning until evening. So, it's quite a long duration. If I don't want to eat that food then I (will be) hungry for the whole (day).

Theme 7: Language barrier as a precursor to racial microaggression

The participants recognized that the reluctance or ignorance of using a common language during the interaction with members of different ethnicities poses a ground for misunderstanding or hindrance from unity. Such a situation happened more often in the presence of members of ethnic Chinese and Indians who tend to speak in their mother tongue, which is not commonly understood by people outside their ethnicities. Such an experience is less applicable to members of ethnic Malay, albeit not wholly true. The people from ethnic Malay usually speak in their mother tongue, which happens to be the Malaysian national language. However, when they speak with a distinctive slang or accent from a particular state in Malaysia, it is not easily understood by people from different ethnicities.

P 23.5 (ethnic Indian): I'm in a group (assignment) and I'm the only different race, while my friends are all Chinese. Then I feel like I've been neglected or something. Because they are discussing in their languagethey are using Chinese, and I cannot understand what they are saying, what they are talking and the decision that they are taking. This thing does not always happen, as I experience only sometimes. They make a decision and give me a task and ask me to do this. They do not like discussing or involving me in their team.

Theme 8: Differential treatment toward people from different ethnicities/ religion

The participants performed or experienced discrimination in an unobvious way due to their ethnic/religious identity. Such a situation may happen to people of equal and unequal status or standing.

P 29.1 (ethnic Indian): An example I can say when with a security guard, the (university dormitory) gate security, it's like nowadays they are very strict with the students, those with cars. So, although if I go with my friends in a car, we are all Indian friends. My friend lives inside the campus (dormitory), then she will send us first. However, the security guard won't allow us. If the car in front of us or behind us is full of their race (same ethnicity with the guard), then they will (be allowed to) go. They (the guards) won't stop the car. This happened just a few days back.

Theme 9: Alien in own land

Participants were regarded as foreigners in their own country despite their citizenship status as Malaysians. This is often experienced by participants of all other ethnicities except for ethnic Malay, as they are classified as Bumiputera in Malaysia. However, this does not apply to the other Bumiputera; that is, the indigenous groups from Sabah and Sarawak.

P 23.2 (ethnic 'Others'): Sometimes, I do feel because when we interact with each other, they notice my slangmy slang is different. So, indirectly they will ask me first, are you a Sarawakian or are you a Sabahan? Or are you an international student? It's kind of like disturbing for me because we are Malaysians, right? So, I think this should not happen.

Theme 10: Denial of racial experience

The participants' experience of racial microaggression was often brushed off, minimized, or ridiculed by their confidant. Some of them were even accused of being oversensitive while deep down there is a nagging voice that something is not right during their encounter with racial microaggression. This is due to the ambiguous and subtle nature of their racist experiences that made it difficult to pinpoint the issue.

P 8.1 (ethnic Malay)

$R$ : When you experienced that when you went to a shop and the staff did not serve you first, have you ever told that experience to your friends?

$P$ : Yes, but not all of my friends. I only told to my close friends.

$R$ : What was your friend's response? Did he support you or...?

$P$ : Yes, he supported me 
$R:$ Is there any friend that has ever said that maybe you are being oversensitive?

P: Someone, he told me, "you don't take it seriously, it is a normal thing.

Theme 11: Preferential interaction with other ethnicities

The participants recounted that they choose to interact with members outside their ethnicity because they attached a negative association to their ethnicity. Such a situation may arise due to experience, socialization, assimilation, or acculturation.

P 22.3 (ethnic Chinese): Yeah in class and university, Malays and other races, Indians. They are quite ok when compared to the Chinese. Actually, in Form 6 (equivalent to a pre-university course), I entered SMK (national high school) right, and I started interacting with Malays. At that time, I feel that Malays are better than Chinese. Then, at that time, our class has an equal number of Malay and Chinese students. I can't interact with a group of Chinese cliques. I belong to the Malay clique.

Table 3 lists the remaining five themes specific to each ethnic group.

Table 3.

Racial microaggression themes experienced by specific ethnic groups

\begin{tabular}{ll} 
No. & Themes, Frequency \& Ethnicities \\
\hline Others & $\begin{array}{l}\text { Pathogizing cultural values/communication style (4) } \\
\text { 2. Ignorant about the situation in Sabah \& Sarawak (4) } \\
\text { Others }\end{array}$
\end{tabular}

3. Explicit racial topic/ racial controversy (2) ethnic Malay

4. Perception of sexual availability (2) ethnic Chinese

5. Assumption of close-mindedness (1) ethnic Indian
Definitions

An act of demeaning the cultural value or communication style of ethnic 'others,' as it is perceived as different from one own.

An ignorance, naiveté, or lack of insight into the reality in Sabah and Sarawak by the Malaysians from peninsular (West) Malaysia.

An act of actively and intentionally promoting one's ethnic interest in a supposedly egalitarian institution.

An experience of sexual harassment or perception of sexual availability due to one's gender and ethnicity

An act of perceiving others as not open to new experiences due to his/ her ethnic identity.

The following are descriptions and samples of transcripts of five ethnic-specific themes:

Theme 1: Pathologizing cultural values/ communication style ('others')

Participants perceived that people of other ethnic groups mocked their ethnicity or parroted their cultural habit to belittle them. They were insulted because their communication style was mocked due to their ethnicity.

P 29.2 (ethnic 'Others')

P: Usually, Sabahan will add suffix 'bah' when they speak. Later, I don't know, maybe they try.

R: You mean they tried to imitate?

P: Yeah.

$R:$ And then they laughed?

P: Yeah.

$R:$ They are students from different races?

P: Yeah.

R: They laughed among themselves with their friends from the same race? And you heard it?

P: Yeah.

$R:$ What did they say?

P: In Peninsular Malaysia, they thought that I'm (a) Chinese. After that, sometimes with students from other races that I don't know, they will make fun (of me). 
Theme 2: Ignorant about the situation in Sabah \& Sarawak ('others')

Participants came across peers from Peninsular Malaysia who were not informed about the reality in Sabah and Sarawak. The participants were troubled by the belittling comments by their ignorant friends who adopt generalized views on the situation in Sabah and Sarawak as rural and less developed.

P 30.1 (ethnic 'Others'): And sometimes people were like... even Sabah is in Malaysia. So when they know we are from Sabah, they (will) ask: "Do you still live on the tree?". Then most of us gonna say (sarcastically) "Yes, we live on the tree." However, we gonna go like "Do you have a lift (elevator) in your home?" It's like being sarcastic to them. Sometimes, people asked us, how did you guys go to school? Most of the time I don't know why people don't know like "Do you have electricity in Sabah?" Something like that. So, it's not good for us. We felt like macam terhina sikit (somewhat insulted).

Theme 3: Explicit racial topic/ racial controversy (ethnic Malay)

Participants witnessed a group of people who pushed forward their racial interest by advocating their preferred political party. They were discouraged because they perceived to be imposed by the lecturer's political interest and were not allowed their political freedom.

P 8.3 (ethnic Malay): I went to my class, my major class. They ask me...the lecturer was Malay and they say We are Malays; we are not like Chinese and we have this kind of benefit like we pay less to buy a car or home and not like Chinese and Indians because we are Bumiputera, that's why you should vote this and this party. This goes to the same with my lecturer who sided the opposition. They said that if you want to make your country more maju (developed), you should not vote for the opposition because of look at the rebel countries like Syria, Arab, and Egypt.

Theme 4: Perception of sexual availability (ethnic Chinese)

Participants were harassed, as they were perceived to be sexually available due to their ethnic identity and gender. They reported that the harassments were in forms of catcalling and inappropriate display of one's genital (possibly showing a symptom of exhibitionistic disorder). The perpetrator was of different ethnicity and the opposite gender. The participants were violated by the harassment and became highly vigilant whenever they encountered a man or a group of men from different ethnicities.

P 22.3 (ethnic Chinese): That time I was walking with my other friend, a Chinese. From the bus station, we were walking to a shop. The street was empty behind the shop. It was quite dark. This happened in the afternoon. A guy was brave enough to show his (genital) to us.

R: Oh my. Did he just suddenly drop his pants and show?

$P:$ Then he asked us to go to him. And another example when I was just, I think in primary school when my sister picked me. Then, a Malay guy was passing us. The guy was on a motor(cycle). That guy also showed his (genital). I also don't know, my sister... I don't know.

P 8.4 (ethnic Chinese): ...the Indian guy call "Amoy" (let's) come together. Indians also do like that. They ask me to join them as (they think) we will join like that, right? But in their feeling...in their thinking a Chinese really can join them like that. But I think I (am) not sure this will happen to Malay girls because normally Chinese (girls) will experience this problem.

Theme 5: Assumption of close-mindedness (ethnic Indian)

Participants were perceived to be close-minded due to their racial identity. They were disappointed with their friends, who avoided them because of such an assumption.

P 29.4 (ethnic Indian): I think of another way on how they receive your openness to a certain topic. They would not address you in a certain way. Private topic. It depends on your openness because I know that there is a generalization that Indians are generally not open to societal problems and stuff like that.

\section{Discussion}

The present study examined the experience of racial microaggression across four groups representing different ethnics in Malaysia, namely ethnic Malay, Chinese, Indians, and others. The discussions are divided into comparing the differences in terms of (i) frequency, (ii) themes, and (iii) variation of themes specific to each ethnic group.

Firstly, we compared the frequency of racial microaggression as experienced by specific ethnic groups. We found that the differences in terms of frequency of racial microaggression experience are minimal across the different ethnic groups. The frequency of racial microaggression among different ethnic groups in this sample ranged from 22 to 29 occurrences. The ethnic Malay and Chinese participants reported the highest frequency, followed by ethnic Indian 
and 'others' participants that reported the slightly lower frequency of racial microaggression themes. Such a finding is unlike those from past studies, whereby there was a higher intensity of racial microaggression experience amongst Native Americans (Jones \& Galliher, 2014) and minority groups (Alabi, 2015; Raza, 2018). In the context of Malaysia, there is generally an equal experience of racial microaggression across the ethnic groups in that anyone can potentially be perpetrators as well as victims. This suggests that at least in the context of Malaysia, racial microaggression can be attributed to intra-/ inter-group interactions rather than merely the interactions of members of minority groups versus majority groups.

Secondly, we examined the themes of racial microaggression as experienced by our sample of different ethnic groups. Overall, 16 racial microaggression themes emerged in the present study. Eleven racial microaggression themes were commonly reported by participants of most ethnic groups, while five themes were pertinent to each ethnic group. The 11 common themes illustrate the shared racial microaggression experience reported across at least two ethnic groups in Malaysia, despite their varying background and national status as majority or minority groups. The findings reflect the shared biases of people interacting with those of different ethnic groups in general.

Interestingly, some of the themes are similar to those of past studies conducted in other countries. For example, 'assumption of superiority/ inferiority/ intelligence due to ethnicity', 'denial of racial experience', and 'differential treatment toward people from different ethnicities/ religions' are consistent with themes from past studies, such as 'ascription of intelligence' and 'denial of individual racism' (Jones \& Galliher, 2014), and 'colleague treated me differently than White colleagues' (Alabi, 2015, p.8). The themes are similar, except for the context and the ethnicities of perpetrators/ victims. These themes may represent the core nature of racial microaggression in that they can be observed across different locations and cultures. Indeed, the assumption of biological differences and differential treatment are the main characteristics of prejudice and racism. Denying experience is another major form of prejudice and racism. However, we also found differences in themes reported in the present study compared to findings in the other studies. One such theme is "Preferential interaction with other ethnicities," in which an ethnic Chinese preferred to interact with ethnic Malays compared to in-group Chinese. In this case, the racial microaggression may be directed at own members of the ethnic group. Future studies need to explore further this "opposite" racial microaggression.

Several ethnic-specific experiences can be observed in this study. For example, 'Alien in own land' was experienced by all ethnicities but the ethnic Malay participants. This might be attributed to the fact that ethnic Malays are considered as the majority and Bumiputera population in Malaysia; therefore, they are not perceived as outsiders. Unfortunately, the same experience might not be shared by the other Bumiputeras, particularly the indigenous groups from Sabah and Sarawak. They reported that they were often mistakenly identified as foreigners or Indonesians (see 'Pathologizing cultural/ communication style') and also due to Peninsular (West) Malaysians' unfamiliarity with the situation in East Malaysia (Sabah and Sarawak) (see 'Ignorant about the situation in Sabah \& Sarawak'). Further details on the experience of ethnic 'Others' are discussed in the later paragraphs.

Meanwhile, ethnic Chinese and Indians attributed their experience of 'Alien in own land' differently. Participants reported that they were often told to return to their so-called homeland, despite their citizenship status and high level of acculturation in the country being an established public knowledge. Ethnics Chinese and Indians in Malaysia are descendants of many generations of early migrants from China and India, respectively (Hirschman, 1987). In Malaysia, the perpetrators were fully aware of their Malaysian citizenship and acculturation status; therefore, 'Alien in own land' may come off as an insult to the victims.

There are also variations in the meaning attributed to 'Second-class citizens' by different ethnic groups. The participants of ethnic Chinese, Indians and 'Others' generally reported being treated unfairly in terms of their statutory rights and more formal areas, such as public university scholarship, seats in student councils, employment opportunities in public sectors, and others. Meanwhile, participants of ethnic Malays reported experience in more informal areas of their everyday lives. Such unjust was often implicit as there was no formally or explicitly stated quotas or regulations that favored specific ethnic groups. The perceived unfairness might have resulted from clashes between one's idealization or expectation of meritocracy versus reality. This is an interesting finding because it highlights how specific policies and practices can creep into people's domain and in turn, shape their experience. Ethnic Chinese, Indians and 'Others'" experience of racial microaggression may be more directly related to differential policies and practices, whereas ethnic Malay's experience may be contributed more to people's reactions to these differential policies and practices.

The experience of 'Assumption of superiority/ inferiority/ intelligence due to ethnicity' was also perceived differently by each ethnic group. Participants of ethnic Malay, ethnic Indian and ethnic 'Others' reported that they were often perceived to be inferior or less intelligence by the rest of the ethnic groups. These participants also reported assuming the ethnic Chinese to be superior or more intelligent. Such stereotypical assumptions are not necessarily accurate and tend to produce unfavorable effects. For example, participants frequently recounted an experience of 
ostracization due to either perceived underestimation or overestimation, burden or responsibility that are uncalled for due to the high expectation, and others. This finding illustrates how racial microaggression themes and experiences are highly determined by the existing stereotypes. Just as overt prejudice and discrimination are heavily connected to stereotypes, racial microaggression also influenced by these stereotypes attributed to different ethnic groups.

Moving on to the discussion of ethnic-specific themes, the 'Others' interviewed in the present study were members of mixed parentage and ethnic groups such as Iban, Bidayuh (Sarawak), Kadazan-Dusun, Bajau, and Bugis (Sabah) from East Malaysia. Most of their religious beliefs and cultures are different from those of the ethnic Malay population from Peninsular (West) Malaysia, which might explain their experience of being perceived as outsiders. Specifically, they reported being often perceived as Indonesians, as Sabah and Sarawak are located in the northern part of Borneo Island. Although many of them speak Malay, their accents and inflections are quite different from those spoken in West Malaysia, which may explain the communication barrier.

The different religious beliefs and cultures of Sabahans and Sarawakians undoubtedly may have contributed to the themes of 'Pathologizing cultural values/communication style' and 'Ignorant about the situation in Sabah \& Sarawak.' According to the participants, their different cultures and communication styles were subjected to constant ridicule by their friends of other ethnicities. Also, due to the location of Sabah and Sarawak at East Malaysia, a separate and distant island from Peninsular (West) Malaysia, many West Malaysians were perceived to be unfamiliar with the reality and situation of East Malaysia. According to the participants, such a lack of knowledge or misinformation was exacerbated by the inaccurate portrayal of a national television documentary on Sabah and Sarawak as rural and less developed parts of the countries. These themes are consistent with 'a colleague has told me that people should not think about race anymore' (Alabi, 2015, p.8), whereby there is an underlying ignorance of different cultures. This highlights the contribution of "compounding" differences and the role of contact in contributing to racial microaggression experience. 'Pathologizing cultural values/communication style' and 'Ignorant about the situation in Sabah \& Sarawak.' are likely to be experienced when the differences between groups are not just in one aspect, i.e., ethnicity but also other aspects, i.e., religion, communication style, and geographical locations. This highlights how religion may play an essential role in intergroup relations and may represent religious microaggression. This concept needs to be further explored. The theme 'Pathologizing cultural values/communication style' may also likely to be directed to groups where the contact and opportunity for interaction are limited.

Another noteworthy ethnic-specific theme is 'explicit racial topic/ racial controversy' experienced by ethnic Malay participants. The participants recounted being imposed by other's political interests; thus, losing their political voice. The perpetrators were members of their ethnic group who were from a higher social position than the participants (in this case, university lecturers). This may have resulted from the nature of the ethnonationalism political situation in Malaysia (Ramasamy, 1993). In this context, the majority ethnic group may be trying to protect their ethnic political agenda against the competing minority ethnic political parties, by purportedly trying to impose their political interest onto the participants. This again highlights how the political agenda of people with power crept into the experience of ordinary citizens.

As suggested earlier, while the common themes indicate the shared biases among people of different ethnic groups, the ethnic-specific themes may reflect the specific perceptions or stereotypes associated with specific ethnic groups. These two sets of findings suggest that both shared and specific biases play an essential role in the occurrences of racial microaggression.

While the study initially set out to investigate the experience of racial microaggression across different ethnic groups, it also discovered the multiple factors relating to racial microaggression experience. Similar to that of past studies from Jones and Galliher (2014) and Elias et al. (2017), other factors outside ethnicity may play a role in attributing to the perpetuation of racial microaggression. Gender difference contributes to the perpetuation of the theme 'perception of sexual availability', such that the perpetrator is a male and the victim is a female. Besides, one's degree of acculturation or negative experience with members of his or her ethnic group contributes to the theme of 'preferential interaction with other ethnicities.' A person's experience of encountering people of different ethnicities may contribute to his/ her preference in socialization.

Religion is another essential factor that contributes to the perpetuation of some racial microaggression themes, such as: 'Insensitivity toward the existence of other ethnicities' and 'Pathologizing cultural values/communication style.' Religions have been playing a prominent role in influencing Malaysian public policies. Such policies are often related to the government's social and economic goals that influence the lives of various ethnic and religious groups in Malaysia (Means, 1978). This suggests that racial microaggression occurred beyond the ethnic difference of the perpetrator and the victim; it can be manifested through the interplay of various identities (gender, degree of acculturation, and religion) (see Arslan, 2019). This indicates the multi-layered nature and complexities of racial microaggression that may prompt more extensive future research. 


\section{Implications of the Present Study}

The findings of this study present several theoretical implications. Firstly, it is argued that racial microaggression is mainly related to the ethnic identity of both perpetrators and recipients and the social categorization associated with their identity. Such a social categorization process is explained by the social identity theory. Tajfel (1974) proposed that social categorization refers to the mental processes in which people divide others into the 'ingroup' and 'out-group,' which affects people's reactions to whom they perceived as belonging to their inner circle versus outer circle. People form their social identity based on self-concept derived from their knowledge of membership of a social group, in addition to the emotional significance related to such membership. Thus, social categorization is a system that provides an individual's place in society by adopting the identity that they belong to. Once they are linked to a particular group identity, they will act, mirror, and attach their self-esteem to that group membership (Tajfel, 1974).

The process of social categorization can potentially be a basis for racial microaggression experiences. It affects the way people view themselves and others, which in turn influences how they react to others of different ethnicities. People react differently, most often negatively, toward those they perceive as the out-groups (Tajfel, 1974). Some reactions are so subtle that they fit into the descriptions of racial microaggression. The findings of 16 themes in the current study are consistent with the social identity theory, in which the distinction and perspectives of in-group versus out-group interactions affect an individual's experience of racial microaggression. Future research is needed to investigate the specific role of in-group and out-group interactions and perceptions in the perpetuation of racial microaggression. The examination of the in-group and out-group should not be limited to ethnicities, but also gender, religion, and other social categories.

Other theoretical implications can also be concluded based on the findings of this study. Firstly, we found some similarities between the experience of racial microaggression in this study and previous studies conducted in societies outside Malaysia. This suggests that there are core characteristics of racial microaggression that can be observed across cultures and locations and they comprise of the assumption of biological differences and differential treatment of people from different ethnicity. The other core characteristics are denying the racial microaggression experience. It is vital to explore this in other cultural contexts and to provide a theoretical explanation as to why they exist. They may be related to survival instincts to be successful in competition to fight for limited resources.

The other important implication from this study is that racial microaggression themes are experienced differently by different ethnic groups depending upon stereotypes and policies and practices of the community. This suggests how stereotypes and policies and practices play a role in shaping the occurrence of racial microaggression. In order to address racial microaggression, we need to work on eradicating these stereotypes, policies, and practices.

We also observed the role of "compounding" differences in which the groups differed not only based on ethnicity but also on other aspects. More studies need to be conducted to understand further how these differences interact with each other and further shape and moderate the experience of racial microaggression. We also highlight the concept of religious microaggression that may be similar to racial microaggression in terms of its threat to society. What is equally alarming is racial microaggression directed at one's group. It is essential to discover the basis of such action and the factors that contribute to people acting aggressively towards their own group.

Indeed, the findings of this study underline the necessity to build a stronger theoretical foundation for racial microaggressions. Development of a more extensive theory to explain the phenomenon should go beyond describing the themes and prevalence of racial microaggression but should set out to outline the mechanisms of which it occurs, the contributing factors leading to its occurrence, and the outcome of the experience. These should be of interest to many researchers in different countries to work on understanding inter-group relationships and not just to researchers in Malaysia or Asia.

The multi-ethnicities findings of racial microaggression present several practical implications. Aside from the implementation of compulsory university modules such as Islamic and Asian Civilizations and Ethnic Relation, multicultural sensibilities and skills are required of those promoting racial microaggression awareness or delivering effective racial microaggression intervention in Malaysian public universities. One can no longer assume racial microaggression to be an exclusive experience of a specific ethnic group - it is a fairly universal experience across all ethnic groups in Malaysia. Even within commonly shared themes, the experience of each ethnicity may vary. Such skills should extend beyond the knowledge of ethnicities in Peninsular Malaysia and more efforts are needed to understand the ethnic 'Others' in East Malaysia (Sabah and Sarawak). Besides, factors beyond ethnicities such as gender, religion, and degree of acculturation should be taken into consideration when promoting racial microaggression awareness or delivering the intervention.

A public university should be an egalitarian institution that practices equality and fairness in its service delivery to everyone regardless of ethnicity. Understanding the mechanisms of racial microaggression may contribute to the importance of creating and promoting awareness to reduce the perpetuation of racial microaggression in all 
layers of university bureaucracy. As we mentioned earlier, it is important to also understand factors contributing to racial microaggression, especially if they are related to specific stereotypes, policies, and practices that exist within a society. Attempts to eradicate stereotypes, policies, and practices that lead to racial microaggression should be implemented.

This study provides evidence of the existence of racial microaggression even among the more highly educated section of the society. There is a concern about the prevalence of the phenomenon among the broader groups of the community. More studies should be conducted across other demographic samples to examine the extent of racial microaggression in Malaysia.

The findings from the present study highlight the real occurrence of racial microaggression across multiple ethnic groups in the Southeast Asian context, particularly in Malaysia. The current study represents a contribution to reducing the racial microaggression literature gap in multi-ethnicities and the Southeast Asian context.

\section{Limitations and Future Directions}

This study is limited in several ways. The sample of the study involved university students. To further understand the experience of racial microaggression across people of different ethnic groups, future studies should include a more extensive demographic sample. Future studies should examine not just the themes but to understand the origins of the themes, such as the contextual conditions in the society that gives rise to such themes. More sophisticated methodologies should be employed to examine this issue more in-depth. Future studies should also continue to understand the role of multiple factors in shaping the experience of racial microaggression.

In conclusion, this study provides a more complex and in-depth understanding of racial microaggression, especially how it is experienced by people of different ethnic groups in a diverse Southeast Asian society. It presents crucial findings and implications of such a phenomenon in the Southeast Asian region in comparison to other countries whereby many racial microaggression studies have been conducted.

\section{Funding Details}

The first author is an international Ph.D. candidate supported by the Universiti Sains Malaysia Fellowship scheme. The research presented in the manuscript was not supported by any direct funding. We declare that there is no conflict of interest.

\section{Biographical Note}

Mitshel Lino is a Ph.D. research fellow and psychology teaching assistant at Universiti Sains Malaysia. Her research interests include the area of social and multicultural psychology. She has been involved in numerous research projects, including grants from ESRC - Newton Ungku Umar, Australian Research Council, and UNICEF.

Intan H.M. Hashim is an Associate Professor and researcher at Universiti Sains Malaysia. Her research interest combines the area of interpersonal relationships with positive psychology. She has been a Principal Investigator in prestigious local and international research projects. She is a professional member of American Psychological Association (APA), International Association of Relationship Research (IARR), International Positive Psychology Association (IPPA), and Persatuan Psikologi Malaysia (PSIMA).

\section{References}

Ab Rahman, H., Abd Rahman, H., Ahmad, N., Nordin, N. A., Mahmud, N., Shaari, R., \& Wahab, S. R. A. (2011). Kajian tinjauan hubungan etnik dalam kalangan pelajar tahun satu di kampus Johor Bahru, Universiti Teknologi Malaysia (UTM). [A study on ethnic relations amongst freshmen in Johor Bahru campus, UTM]. Sains Humanika, 54(1), 65-76.

Akun, A., \& Andreani, W. (2016). Microaggression and diversity: Tracing Indonesian university students' attitudes toward pluralism through metaphorical creative expressions. Bharatiya Prajna: An Interdisciplinary Journal of Indian Studies, V1N1, 75-89.

Alabi, J. (2015). Racial microaggressions in academic libraries: Results of a survey of minority and non-minority librarians. The Journal of Academic Librarianship, 41, 47-53. doi: 10.1016/j.acalib.2014.10.008

Allen, Q. (2010). Racial microaggressions: The schooling experiences of Black middle-class males in Arizona's secondary schools. Journal of African American Males in Education, 1(2), 125-143.

Arslan, S. (2019). Language, religion, and emplacement of Zazaki speakers. Journal of Ethnic and Cultural Studies, 6(2), 11-22. https://doi.org/10.29333/ejecs/244

Asamen, J. K., \& Berry, G. L. (1987). Self-concept, alienation, and perceived prejudice: Implications for counseling Asian Americans. Journal of Multicultural Counseling and Development, 15(4), 146-160. doi: 
10.1002/j.2161-1912.1987.tb00390.x

Calderon Berumen, F. (2019). Resisting assimilation to the melting pot: Validating the cultural curriculum of the home. Journal of Culture and Values in Education, 2(1), 81-95. Retrieved from http://cultureandvalues.org/index.php/JCV/article/view/25

Constantine, M. G. (2007). Racial microaggressions against African American clients in cross-racial counseling relationships. Journal of Counseling Psychology, 54, 1-16. doi:10.1037/0022-0167.54.1.1

Constantine, M. G., \& Sue, D. W. (2007). Perceptions of racial microaggressions among black supervisees in crossracial dyads. Journal of Counseling Psychology, 54(2), 142-153. doi: 10.1037/0022-0167.54.2.142

Department of Statistics Malaysia (2018). Press release current population estimates, Malaysia, 2017-2018. Retrieved from

https://www.dosm.gov.my/v1/index.php?r=column/pdfPrev\&id=c1pqTnFjb29HSnNYNUpiTmNWZHArdz 09

Elias, T., Jaisle, A., \& Morton-Padovano, C. (2017). Ethnic identity as a predictor of microaggressions toward Blacks, Whites, and Hispanic LGBs by Blacks, Whites, and Hispanics. Journal of Homosexuality, 64(1), 1-31. doi: 10.1080/00918369.2016.1172888

Fan, S. H., \& Ni, H. P. (2013). The dormant outcome of racial microaggressions in Taiwan: Language-delayed mixed children and their immigrant mothers. US-China Education Review, 3(10), 735-748.

Hashim, I.H.M., Mohd-Zaharim, N. \& Khodarahimi, S. (2012). Perceived similarities and satisfaction among friends of the same and different ethnicity and sex at workplace, Interpersona, 6 (2), 191-199 doi:10.5964/ijpr.v6i2.100

Hirschman, C. (1987). The meaning and measurement of ethnicity in Malaysia: An analysis of census classification, The Journal of Asian Studies, 46(3), 555-582.

Houshmand, S., Spanierman, L. B., \& Tafarodi, R. W. (2014). Excluded and avoided: Racial microaggressions targeting Asian international students in Canada. Cultural Diversity and Ethnic Minority Psychology, 20(3), 377-388. doi: 10.1037/a0035404

Husain, F. C., \& Kadir, F. A. A. (2012). Sumbangan pengajian kursus tamadun Islam dan tamadun Asia (TITAS) terhadap pembentukan hati budi mahasiswa di Institusi Pengajian Tinggi Awam (IPTA) Malaysia [Contribution of the Islamic and Asia Civilization (TITAS) towards Holistic Formation of Students]. Journal of Al-Tamaddun, 7(1), 15-35.

James, W. Y. (2019). Imprint of Racism: White Adult Males' Transformational Experience from Racial Antipathy to Racial Reconciliation. American Journal of Qualitative Research, 3(1), 93-116. https://doi.org/10.29333/ajqr/5813

Jones, M. L., \& Galliher, R. V. (2014). Daily racial microaggressions and ethnic identification among Native American young adults. Cultural Diversity and Ethnic Minority Psychology. Advance online publication. doi: http://dx.doi.org/10.1037/a0037537

Kessler, C. S. (1992). Archaism and modernity: Contemporary Malay political culture. In J. S. Kahn \& F. K. W. Loh (Eds.), Fragmented vision, culture and politics in contemporary Malaysia (pp. 133-157). North Sydney, NSW, Australia: Asian Studies Association of Australia in association with Allen and Unwin.

Langdridge, D. (2004). Introduction to research methods and data analysis in Psychology. Essex: Pearson Education Limited.

Lee, H. A. (2012). Affirmative action in Malaysia: Education and employment outcomes since the 1990s. Journal of Contemporary Asia, 42(2), 230-254.

Lin, A. I. (2010). Racial microaggressions directed at Asian Americans: Modern forms of prejudice and discrimination. In D. W. Sue (Ed.), Microaggressions and marginality: Manifestation, dynamics, and impact (pp. 85-103). Hoboken, NJ: Wiley.

Lincoln, Y. S., \& Guba, E. G. (1985). Naturalistic inquiry. Newbury Park, CA: Sage Publications.

Lino, M. (2010). Racial microaggression experienced by Malaysian college students in HELP University College, Malaysia (Unpublished undergraduate thesis). HELP University College, Kuala Lumpur.

Lino, M., Hashim, I.H.M., \& Ricardo, R. (2017). The lurking racism: Exploring racial microaggression in Malaysian university setting. Pertanika Journal of Social Sciences \& Humanities, 25(1), 473 - 484.

Means, G. P. (1978). Public policy toward religion in Malaysia. Pacific Affairs, 51(3), 384-405. doi:10.2307/2757937 Mustapha, R., Azman, N., Karim, F., Ahmad, A. R., \& Lubis, M. A. (2009). Social integration among multi-ethnic 
students at selected Malaysian universities in Peninsular Malaysia: A survey of campus social climate. ASEAN Journal of Teaching and Learning in Higher Education (AJTLHE), 1(1), 35-44.

Nagaraj, S. (2009). Intermarriage in malaysia. Malaysian Journal of Economic Studies, 46(1), 75-92. Retrieved from https://search.proquest.com/docview/312317967?accountid=14645

Nasir, N. F. M., Ghani, F. A., Salamat, M., \& Husain, S. (2018). Kajian kerelevanan pendidikan ketamadunan (Subjek mata pelajaran umum: Tamadun Islam dan Tamadun Asia - Titas) di salah sebuah universiti swasta, Selangor. [A study on the relevance of civilization education (the Islamic and Asia Civilization -Titas]. International Journal of Education, Psychology and Counseling, 3(18), 46-54.

Neo, H. (2012). "They hate pigs, Chinese farmers... everything!" Beastly Racialization in Multiethnic Malaysia. Antipode, 44(3), 950-970.

Noor, N. M. (2007). Polarisation and inequality in Malaysia: The future of Malay-Chinese relations. Intellectual Discourse, 15(2), 191-204.

Pierce, C. M., Carew, J. V., Pierce-Gonzalez, D., \& Wills, D. (1977). An experiment in racism: TV commercials. Education and Urban Society, 10(1), 61-87. doi: 10.1177/001312457701000105

Raman, S. R., \& Tan, Y. S. (2010). Ethnic segregation in Malaysia's education system: Enrolment choices, preferential policies and desegregation. Paedagogica Historica, 46(1-2), 117-131. doi: 10.1080/00309230903528496

Ramasamy, R. (1993). Racial inequality and social reconstruction in Malaysia. Journal of African and Asian Studies, 28(3-4), 217-229.

Raza, K. (2018). The Muddy Waters of Multicultural Acceptance: A Qualitative Case Study on Antisemitism and the Israeli/Palestinian Conflict. Journal of Ethnic and Cultural Studies, 5(1), 1-15.

Rivera, D. P., Forquer, E. E., \& Rangel, R. (2010). Microaggressions and the life experience of Latina/o Americans. In D. W. Sue (Ed.), Microaggressions and marginality: Manifestations, dynamics, and impact (pp. 59 - 83). Hoboken, NJ: Wiley.

Schmitt, M. T., \& Branscombe, N. R. (2002). The meaning and consequences of perceived discrimination in disadvantaged and privileged social groups. In W. Stroebe \& M. Hewstone (Eds.), European review of Social Psychology (2002), V. 12, (pp. 167-199). Chichester.

Segawa, N. (2007). Malaysia's 1996 Education Act: The impact of a multiculturalism-type approach on national integration. Sojourn: Journal of Social Issues in Southeast Asia, 22(1), 30-56. doi: 10.1355/sj22-lb

Silalahi, R., \& Yuwono, U. (2018). The sustainability of Pancasila in Indonesian education system. Research in Social Sciences and Technology, 3(2), 58-78. Retrieved from http://ressat.org/index.php/ressat/article/view/364

Sue, D. W. (2004). Whiteness and ethnocentric monoculturalism: Making the "invisible" visible. American Psychologist, 59, 759-769.

Sue, D. W., Capodilupo, C. M., \& Holder, A. M. B. (2008). Racial microaggressions in the life experience of Black Americans. Professional Psychology: Research and Practice, 39, 329 -336. doi:10.1037/ 07357028.39.3.329

Sue, D. W., Capodilupo, C. M., Torino, G. C., Bucceri, J. M., Holder, A., Nadal, K. L., \& Esquilin, M. (2007b). Racial microaggressions in everyday life: Implications for clinical practice. American Psychologist, 62(4), 271.

Sue, D.W., Bucceri, J. M., Lin, A.I., Nadal K. L., \& Torino, G. C. (2007a). Racial microaggressions and the Asian American experience. Cultural Diversity and Ethnic Minority Psychology, 13(1), 72-81. doi: 10.1037/10999809.13.1.72

Tajfel, H. (1974). Social identity and intergroup behavior. Social Science Information, 13, 65-93. doi:10.1177/053901847401300204

Tamam, E., \& Krauss, S. E. (2017). Ethnic-related diversity engagement differences in intercultural sensitivity among Malaysian undergraduate students. International Journal of Adolescence and Youth, 22(2), 137-150. doi: $10.1080 / 02673843.2014 .881295$

Tuitt, F. A., \& Carter, D. J. (2008). Negotiating atmospheric threats and racial assaults in predominantly white educational institutions. Journal of Public Management \& Social Policy, 51-68.

Tzannatos, Z. (1991). Reverse racial discrimination in higher education in Malaysia: Has it reduced inequality and at what cost to the poor? International Journal of Educational Development, 11(3), 177-192. doi: 10.1016/07380593(91)90018-4

Wang. J., Leu. J. X., \& Shoda, Y. (2011). When the seemingly innocuous "stings": Racial microaggressions and their emotional consequences. Personality and Social Psychology Bulletin, 37(12), 1666-1678. doi: 
$10.1177 / 0146167211416130$

Wong-Padoongpatt, G., Zane, N., Okazaki, S., \& Saw, A. (2017). Decreases in implicit self-esteem explain the racial impact of microaggressions among Asian Americans. Journal of Counseling Psychology, 64(5), 574-583. doi: $10.1037 /$ cou0000217

Wong, G., Derthick, A.O., David, E.J.R., Saw, A., \& Okazaki, S. (2014). The what, the why, and the how: A review of racial microaggressions research in psychology. Race and Social Problems. 6(2), 181-200. doi:10.1007/s12552-013-9107-9

Yamada, A., \& Yusa, T. (2014). Ethnic microaggressions: The experiences of Zainichi Korean students in Japan. InterActions: UCLA Journal of Education and Information Studies, 10(2). Retrieved from https://escholarship.org/uc/item/8620q2

Yigit, I. H., \& Tatch, A. (2017). Syrian refugees and Americans: Perceptions, attitudes and insights. American Journal of Qualitative Research, 1(1), 13-31.

\section{Appendix}

\section{List of Semi-Structured Interview Questions}

General question on racial microaggression

1. It is common for you to interact with friends, roommates, classmates, lecturers, and other staff of different ethnicities in the university every day. Can you describe some of the subtle ways you were treated differently because of your ethnicity? Please give some examples.

For every question in the following, the first researcher probed for more details of: 'who,' 'what,' 'where,' 'when,' 'how' subsequently after each question.

Specific questions on some Racial microaggression scenario

2. Have you ever been called a bad name due to your ethnicity, in a private situation whereby there is just you and the other person?

3. Have you been physically attacked due to your ethnicity, in a private situation where there is just you and the other person?

4. Has anyone ever insulted your culture or ethnicity by making insensitive remarks?

5. Has anyone ever ignored you because of your ethnicity?

6. Has anyone ever ignored your ideas or feelings because of your ethnicity?

7. Has anyone ever suggested that you should not be here because of your ethnicity? 